KAWISTARA

VOLUME 6

No. 1, 21 April 2016

Halaman 1-112

\title{
CANDU DAN MILITER \\ KETERLIBATAN BADAN-BADAN PERJUANGAN DALAM PERDAGANGAN CANDU DI JAWA PADA MASA REVOLUSI
}

\author{
Julianto Ibrahim \\ Jurusan Sejarah Fakultas Ilmu Budaya \\ Universitas Gadjah Mada \\ Email: juliantoibrahim@ugm.ac.id
}

\begin{abstract}
During revolution era, Indonesian government used and traded opium for struggle funds. This decision was based on the fact that the social, economic and financial was shattered due to Japanese occupation. Whereas the government should provide substantial funds to pay the war operations, employee salaries and soldiers, buy weapons of war, and pay representatives abroad. This paper constitutes as the result of historical studies, that is why it uses historical method and methodologies. Historical method constitutes as a historian guidelines to find historical documents. Historian is like "handyman" who collects historical sources such as archives and documents in "warehouses" archives and libraries. When written sources are considered as not enough, then those will be held interviews with historical actors involved directly or indirectly to the problem under study. Historical method constitutes a works of historian from processing facts, explanations to the reconstruction of the results under study. Methodology provides the framework of thinking as historian, that is why, it needs to pay attention to the concepts and theories in preparing the events of the past. This study is based on the method from Ernst Bernheim, that are heuristic, criticism, auffassung and darstellung. Indonesian government fully managed and controlled the opium trade and circulation in Java. The management was led by the Vice President Office assisted by two ministries, namely the Ministry of Finance and Ministry of Defence Quartermaster Section. Under those two ministries, there was the Mayor Administrative Office of Opium and Salt in Surakarta which coordinated major offices in several cities, especially in Kediri and Yogyakarta. The Administrative Office of Opium and Salt in Kediri stored raw opium. Then, raw opium was sent to processing factory in Wonosari and Beji Klaten. The cooked opium was sent to The Administrative Office of Opium and Drug in Yogyakarta or The Mayor Administrative Office of Opium and Salt in Surakarta. This office in Surakarta authorized to issue raw opium to the struggle agencies to be sold to the territory of republic, occupied Netherlands area or smuggled abroad.
\end{abstract}

Keywords: Opium; The Administrative Office of Opium and Salt; Opium trade; The struggle agencies; Revolution era.

\section{ABSTRAK}

Pada masa revolusi, pemerintah Indonesia menggunakan dan memperdagangkan candu untuk dana perjuangan. Keputusan ini didasarkan pada kenyataan bahwa kondisi sosial, ekonomi dan keuangan yang porak poranda akibat kependudukan Jepang. Padahal pemerintah harus menyediakan dana yang besar untuk membiayai operasional perang, gaji pegawai dan tentara, membeli alat-alat perang, dan membiayai perwakilan di luar negeri. Tulisan ini merupakan hasil kajian sejarah sehingga menggunakan metode dan metodologi sejarah. Metode sejarah merupakan pedoman seorang sejarawan dalam memburu dokumen-dokumen sejarah. Sejarawan bagaikan "tukang" yang bertugas mengumpulkan sumber-sumber sejarah berupa arsip maupun dokumen dokumen di "gudang-gudang" arsip maupun 
perpustakaan-perpustakaan. Bilamana sumber tertulis dirasa kurang maka akan diadakan wawancara dengan pelaku sejarah yang terlibat langsung maupun tidak langsung terhadap masalah yang diteliti. Metodologi sejarah merupakan kerja sejarawan dari pengolahan fakta, eksplanasi hingga rekonstruksi dari hasil yang diteliti. Metodologi memberi kerangka berpikir seorang sejarawan, sehingga perlu memperhatikan konsep-konsep dan teori-teori dalam menyusun peristiwa masa lampau. Penelitian ini berpatokan pada metode dari Ernst Bernheim, yaitu heuristik, kritik, auffassung dan darstellung. Pemerintah Indonesia mengelola dan mengendalikan sepenuhnya perdagangan dan peredaran candu di Jawa. Pengelolaannya dipimpin langsung oleh Kantor Wakil Presiden dibantu dengan dua kementerian yaitu Kementerian Keuangan dan Kementerian Pertahanan Bagian Intendans. Di bawah dua kementerian itu terdapat Kantor Besar Regi Candu dan Garam di Surakarta yang mengkoordinasikan kantor-kantor besar di beberapa kota terutama Kediri dan Yogyakarta. Kantor Regi Candu dan Garam di Kediri menyimpan candu yang masih mentah. Lalu candu mentah itu dikirim ke pabrik pengolahan di Wonosari dan Beji Klaten. Candu yang sudah matang dikirim ke kantor regi candu dan obat di Yogyakarta atau ke Kantor Besar Regi Candu dan Garam di Surakarta. Kantor Candu di Surakarta ini berwenang mengeluarkan candu mentah ke badan-badan perjuangan untuk dijual ke masyarakat di wilayah republik, wilayah pendudukan Belanda atau diselundupkan ke luar negeri.

Kata Kunci: Candu; Kantor regi candu dan garam, Perdagangan candu, Badan-badan perjuangan, Masa revolusi

\section{PENGANTAR}

Candu merupakan sejenis bahan minuman yang diperoleh dari tanaman papaver somniferum. Bahan minuman ini mengandung racun yang dapat melemahkan syarafsyaraf tubuh manusia, dan apabila dipergunakan berlebihan akan menyebabkan efek memabukkan. Candu dalam istilah umum disebut sebagai opium yang berasal dari bahasa latin yaitu apion. Orang arab menyebutnya apian dan orang Indonesia menyebutnya dengan apiun. Orang Jawa menyebutnya dengan apyun apabila masih mentah, sedangkan bila sudah matang disebut dengan candu atau madat. Bila pemasakan bahan candu tersebut dicampuri bahan-bahan lain, seperti daun awar-awar, kecubung, atau lengkeng, maka orang Jawa menyebutnya sebagai tike (Djoko, 1970: 1) .

Candu bukan merupakan barang asli Indonesia. Barang ini sudah lama dikenal di daerah Asia Barat dan Eropa Selatan. Bangsa Sumeria telah mengenal candu pada millinia keempat Sebelum Masehi (SM). Bangsa Mesir telah menggunakan candu pada tahun 1550 SM, sedangkan bangsa Assyria bahkan telah pandai membuat tablet dari bahan candu. Cerita-cerita mengenai penggunaan candu di Yunani dan Romawi banyak ditulis oleh para sejarawan seperti Herodotus, Hipocrates, Vergil, maupun Homerus (Djoko, 1970: 14).

Beberapa sumber menyebutkan bahwa candu berasal dari daerah-daerah di Asia Barat, terutama Asia Kecil. DIkarenakan tumbuhan papaver berasal dari daerah ini. Oleh karena itu, penyebaran candu ke seluruh dunia dilakukan oleh orang-orang dari Asia Barat, terutamanya bangsa Arab. Banyak orang menduga bahwa candu menyebar ke Benua Asia dilakukan oleh Bangsa Arab sebelum kelahiran Nabi Muhammad SAW. Daerah tujuan penyebaran candu adalah India, kemudian berkembang ke Cina dengan melalui Birma dan Yunan. Pada saat Portugis berhasil menguasai beberapa bandar perdagangan di Asia, perdagangan candu ikut pula dikuasai oleh para pedagang Bangsa Portugis. Perdagangan semakin meningkat ketika orang-orang Inggris dan Belanda ikut terlibat dalam perdagangan barang ini. Bahkan setelah bandar-bandar perdagangan di Asia berhasil direbut oleh Inggris dan sebagian oleh Belanda, maka monopoli perdagangan candu dikuasai oleh Inggris dan Belanda. Ketika Inggris dapat menguasai India, kompani dagang Inggris yaitu East India Company (1781) berhasil memonopoli perdagangan candu di seluruh dunia. Sejak saat itu, ekspor candu dari India ke daerah Asia lainnya termasuk Indonesia dipegang langsung oleh maskapai tersebut (Djoko, 1970: 17-18). 
Pedagang-pedaganag Arab merupakan pemasok candu di Pulau Jawa. Ketika orangorang Belanda pertama kali mendarat di pulau Jawa pada akhir abad ke-17, candu sudah menjadi komoditi penting dalam perdagangan regional (Rush, 2000: 26). Dalam usahanya untuk mendominasi perdagangan lokal selama abad-abad berikutnya, para saudagar Belanda bersaing dengan orangorang Inggris, Denmark, dan Arab. Pada tahun 1677, akhirnya Kompeni Hindia Timur Belanda (VOC) berhasil membuat sebuah perjanjian dengan Raja Amangkurat II di Jawa yang menjamin diberikannya monopoli kepada VOC untuk mengimpor candu ke dalam wilayah kerajaannya (Mataram) dan memonopoli untuk mengedarkannya ke dalam negeri. Sejak perjanjian ini hingga tahun 1799, VOC membawa rata-rata 56.000 kilogram candu (opium) ke Jawa setiap tahunnya (Rush, 2000: 26-27).

Pada akhir abad ke-19, peredaran candu semakin meluas di pulau Jawa terutama di daerah pesisir utara dengan kota-kota pelabuhan serta daerah Surakarta dan Yogyakarta yang padat penduduknya. Peter Carey menulis bahwa, pada tahun 1820 ada lebih dari 372 tempat-tempat terpisah di Yogyakarta dan Surakarta yang menerima lisensi untuk menjual candu, yaitu hampir setiap pos bea cukai utama, subpos cukai dan pasar-pasar di Kasultanan dan Kasunanan (Carey, 1984:33). Seiring dengan kekuasaan pemerintah Belanda yang semakin besar dan permintaan candu di Jawa yang semakin meningkat, maka pemerintah Belanda memberikan izin pula pada pembukaaan bandar-bandar candu di kota-kota besar di pulau Jawa. Kepemilikan bandar-bandar candu tersebut melalui lelang yang biasanya dihadiri dan dipimpin langsung oleh seorang residen. Seorang juru tulis dengan bahasa Melayu membacakan syarat-syarat kompetisi; ditentukannya wilayah kerja bandar, ditunjukkan besarnya opium (candu) yang akan diberikan oleh pemerintah bagi bandar yang bersangkutan, dan disebutkannya jumlah toko-toko opium yang ada di dalam wilayah kerja bandar tersebut. Seorang residen berkepentingan menghadiri pelelangan ini untuk memastikan siapa yang memenangkan lelang agar bisa dilakukan pembicaraan mengenai besarnya pajak yang harus dibayar oleh seorang pemilik bandar opium (Rush, 2000: 44-45). Orang-orang Cina biasanya lebih unggul dalam pelelangan karena menggunakan banyak cara untuk mendapatkannya seperti penyuapan, penggalangan dengan beberapa kongsi Cina lainnya, atau mencari dukungan dari residen atau pejabat-pejabat Belanda (Rush, 2000: 44).

Daerah yang mempunyai bandarbandar besar opium dan ditempati oleh syahbandar-syahbandar Cina yang terkuat di Jawa adalah Kediri, Semarang, Jakarta, Surakarta, dan Yogyakarta. Beberapa Syahbandar Cina yang pernah menguasai bandar-bandar candu di Kediri adalah Tan Long Haij, Lim Tiong Yong, dan Kwee Swie Tjoan. Bandar-bandar candu di Surakarta dikuasai oleh beberapa syahbandar, seperti Tio Siong Mo, Be Biauw Tjoan, Tan Tong Haij, dan Ho Tjiauw Ing. Syahbandar opium yang paling berjaya di Surakarta dan menguasai hampir perdagangan candu di seluruh Jawa adalah Tio Siong Mo. Pada tahun 1860-an, Syahbandar Cina ini menguasai delapan belas tempat pengolahan candu di Surakarta yang mampu memasok kebutuhan candu ke kota-kota di Jawa. Usaha Tio mengalami penurunan ketika Be Biauw Tjoan melakukan penyeludupan candu dan membentuk pasar-pasar gelap yang menyebabkan hancurnya bandarbandar candu milik Tio. Penyelundupan candu dilakukan oleh sebuah sindikat yang sangat rapi dan didukung oleh syahbandarsyahbandar Cina pada beberapa kota di Jawa. Be Biauw Tjoan merupakan salah seorang penyelundup candu yang memasok candu-candu selundupan ke Surakarta. Rute penyelundupan candu adalah masuk melalui pantai utara Surabaya, lalu Madiun dan berakhir di Surakarta. Jalur penyelundupan lainnya adalah melalui Juwana, Rembang, Lasem, lalu ke Blora, dan terus ke Surakarta. Candu hasil selundupan dan dijual di pasar- 
pasar gelap dengan harga yang lebih rendah dari harga resmi hingga setengahnya. Tio akhirnya dipenjara pada tahun 1870 karena tidak mampu membayar pajak kepada pemerintah hingga 1,5 juta gulden. Sebagian bandar-bandar Tio kemudian dikuasai oleh Tan Tong Haij. Syahbandar Tan pun gagal mengelola bandar candu dan menjualnya kepada Syahbandar Ho Lam Yo yang menguasai bandar candu di Semarang. Pada saat bandar-bandar Ho Lam Yo mengalami kebangkrutan di Semarang, Yogyakarta, dan Kedu pada tahun 1889, Ho Tjiauw Ing salah seorang anak Ho Lam Yo masih dapat bertahan mengelola bandar candu di Surakarta (Rush, 2000: 77-78).

Sistem perdagangan candu melalui bandar-bandar yang dikuasai oleh orangorang Cina mulai dikritik oleh orangorang anti bandar candu seperti Elout van Soetoerwoede. Elout berhasil membentuk organisasi Anti Opium Bond pada tahun 1888 yang beranggotakan 510 anggota yang terdiri dari 440 orang di Belanda dan 70 orang di Hindia (Elout van Soeterwoude, 1890). Kritikan yang terus menerus tersebut memaksa pemerintah Hindia Belanda menghapuskan sistem bandar dan menggantinya dengan regi opium pada tahun 1894. Penggantian sistem ini didasarkan pula pada upaya untuk menekan penyelundupanpenyelundupan opium yang tidak dapat dikontrol selama pelaksanaan sistem bandar (Rush, 2000: 206).

Pelaksanaan regi opium memungkinkan pengelolaan opium yang lebih besar oleh pemerintah Hindia Belanda. Pemerintah mempunyai kekuasaan untuk memproduksi dan mendistribusikan opium kepada outletoutlet grosiran dan kemudian memberikan lisensi kepada agen-agen lokal untuk melayani perdagangan eceran. Sistem ini bertahan hingga berakhirnya kekuasaan kolonial Belanda dan kemudian dijadikan model pengelolaan candu di Indonesia selama masa revolusi. Hal itu terbukti dengan terbentuknya Kantor Regi Candu dan Garam yang berpusat di Surakarta dibawah pimpinan Soewahjo. Setelah terbentuknya kantor besar itu, beberapa daerah di Jawa segera terbentuk kantor-kantor yang mengurusi candu, seperti Kantor candu dan obat di Yogyakarta, kantor candu dan garam di Kediri, dan Kantor-kantor candu lainnya. Kantor-kantor candu ini tidak saja mengelola kebutuhan candu untuk rumah-rumah sakit (Arsip Rekso Pustoko, no. S. 2091) atau kegiatan-kegiatan ritual dari Kraton (Arsip Rekso Pustoko, no. S. 1360), tetapi melakukan pula usaha-usaha rahasia bersama dengan Kementerian Pertahanan dengan menyediakan candu untuk diperdagangkan oleh badan-badan perjuangan sebagai dana revolusi (Ibrahim, 2013: 79-92).

Faktor pendorong yang menyebabkan pemerintah memilih candu sebagai dana perjuangan adalah kondisi sosial, ekonomi, dan keuangan yang porak poranda akibat pendudukan militer Jepang. Pemerintah republik menyadari bahwa sumber-sumber ekonomi dalam sektor pertanian dan perkebunan tidak dapat diandalkan karena sebagian besar pabrik-pabrik pengolahan hasil perkebunan hancur akibat pendudukan Jepang. Selain itu, hasil-hasil pertanian telah banyak terkuras untuk kepentingan penyediaan logistik perang bagi serdadu-serdadu Jepang. Kalaupun masih terdapat cadangan hasil pertanian atau perkebunan, pemerintah sulit menjual atau mengekspornya karena blokade-blokade yang dilakukan oleh Belanda (Ibrahim, 2013: 130-131).

Sebagai upaya untuk mendapatkan dana perjuangan, keterlibatan badan-badan perjuangan dalam memperdagangkan candu sangat penting. Badan-badan perjuangan tidak hanya sebagai tenaga keamanan tetapi melakukan sendiri aktivitas perdagangan candu. Hasil perdagangan candu tidak hanya untuk negara, akan tetapi digunakan pula oleh badan-badan perjuangan memenuhi kebutuhan sendiri baik untuk pakaian, senjata maupun gaji. Badan-badan perjuangan tidak hanya memperdagangkan candu di daerah republik, tetapi juga melakukan penyelundupan ke luar negeri, terutama ke Singapura. 
Setelah melihat uraian di atas, maka masalah yang akan dibahas dalam artikel ini sebagai berikut: (1) Pengelolaan peredaran dan perdagangan candu di seluruh Jawa dalam upaya mencari dana untuk perjuangan. (2) Penyebab badan-badan perjuangan terlibat dalam perdagangan candu di Jawa pada masa revolusi. (3) Cara yang digunakan oleh badan-badan perjuangan dalam melakukan perdagangan candu di Jawa. (4) Cara badan-badan perjuangan melalukan penyelundupan candu keluar negeri.

\section{PEMBAHASAN \\ Pengelolaan Candu di Jawa pada Masa Revolusi}

Pada masa revolusi, pemerintah Indonesia yang baru merdeka mempunyai kepentingan besar terhadap pengelolaan dan perdagangan candu. Pemerintah republik menyadari bahwa sumber-sumber ekonomi dalam sektor pertanian dan perkebunan tidak dapat diandalkan karena sebagian besar pabrik-pabrik pengolahan hasil perkebunan hancur akibat pendudukan Jepang. Selain itu, hasil-hasil pertanian telah banyak terkuras untuk kepentingan penyediaan logistik perang bagi serdadu-serdadu Jepang (Ibrahim, 2004: 1-10). Kalaupun masih terdapat cadangan hasil pertanian atau perkebunan, pemerintah sulit menjual atau mengekspornya karena adanya blokade-blokade yang dilakukan oleh Belanda.

Blokade-blokade tersebut memaksa pemerintah republik melakukan penyelundupan hasil perkebunan ke luar negeri terutama Singapura. Walaupun penyelundupan komoditi perkebunan dapat membantu dana perjuangan, tetapi tidak setiap pejuang bersedia melakukan kegiatan berbahaya ini. Banyak pejuang yang melakukan penyelundupan mengalami nasib yang buruk, seperti ditangkap Belanda atau bahkan meninggal dalam kecelakaan di laut (Mochtar, 1992; George M.C. Turnan Kahin, 1995:296-318). Oleh karena itu, upaya-upaya penyelundupan tidak dapat sepenuhnya diharapkan untuk membantu republik dalam memperoleh dana perjuangan.
Kesulitan dalam bidang ekonomi tersebut diperparah dengan tidak berkembangnya sektor keuangan. Pada masa revolusi terjadi kekacauan dalam penggunaan mata uang. Pada masa itu beredar tiga mata uang di masyarakat, yaitu mata uang Jepang, mata uang NICA, dan mata uang Republik Indonesia (ORI). Pemerintah kesulitan untuk meng-hentikan peredaran kedua mata uang asing, yaitu Jepang dan NICA karena sudah terlanjur dipergunakan oleh masyarakat. Bahkan nilai mata uang RI (ORI) mempunyai nilai yang lebih rendah dibandingkan kedua nilai mata uang asing tersebut (Arsip Rekso Pustoko, no. S.875).

Kondisi ekonomi yang tidak menguntungkan tersebut berdampak pada pemberian gaji kepada pegawai pemerintah dan penyediaan dana untuk perjuangan. Pemerintah harus menyediakan uang yang sangat besar untuk membeli perlengkapan perang dan menyediakan logistik atau perbekalan bagi para pejuang. Senjata dan amunisi yang dimiliki oleh para pejuang sebagian besar merupakan hasil rampasan dari para serdadu Jepang (Arsip Rekso Pustoko, no. S. 2747). Persenjataan tersebut belum mencukupi kebutuhan untuk perjuangan. Hal itu terlihat dengan masih banyaknya pejuang atau laskar-laskar yang tidak memegang senjata. Beberapa pejuang masih mengandalkan senjata-senjata tajam yang dianggap memiliki unsur magis, seperti keris atau pedang dan bambu runcing. Dengan demikian, pemerintah harus menyediakan dan membeli senjata untuk memenuhi kebutuhan para pejuang dalam mempertahankan kemerdekaan Indonesia. Padahal pemerintah tidak memiliki devisa (mata uang asing) yang dapat dipergunakan untuk membeli senjata di luar negeri.

Untuk mengatasi masalah dana perjuangan tersebut, pemerintah secara diamdiam menggunakan candu yang dianggap dapat segera menyediaan dana secara cepat untuk kebutuhan perjuangan. Hal itu terlihat dari beberapa surat permintaan dari kementerian keuangan kepada kementerian pertahanan atau kantor kepolisian agar 
membantu memperdagangkan candu untuk dana perjuangan. Dalam suratnya kepada kepala kepolisian negara yaitu Soekanto, Menteri Keuangan Mr. A.A. Maramis meminta kepolisian membantu memperdagangkan candu yang akan dipergunakan untuk membiayai delegasi Indonesia keluar negeri, membiayai delegasi Indonesia di Jakarta, dan memberi gaji kepada pegawai-pegawai RI. Menteri keuangan juga meminta kepolisian mengizinkan para pejabat kantor regi candu yang membawa lisensi dari kementerian keuangan untuk menjual candu keluar negeri, menukarkan candu dengan emas, dan menukarkan candu dengan mata uang asing (Djogdja Documenten no. 230, ANRI, Jakarta).

Untuk memperlancar pengelolaan dan perdagangan candu, pemerintah membentuk kantor-kantor regi candu di beberapa kota yang dianggap strategis. Kantor-kantor candu yang dianggap besar adalah Kantor Regi Candu dan Garam di Kediri, Kantor Besar Regi Candu dan Garam di Surakarta, dan Kantor Depot Regi Candu serta Obat di Yogyakarta. Kantor-kantor candu tersebut tidak diketahui dengan pasti kapan dibentuk, tetapi berdasarkan dokumen-dokumen yang dihimpun oleh mata-mata Belanda NEFIS (Djogdja Documenten), mereka mulai aktif sekitar pertengahan atau akhir tahun 1947. Selain itu, tempat kedudukan kantor-kantor candu tersebut juga tidak dapat diketahui secara pasti. Beberapa dokumen tentang surat menyurat yang terdapat kop resminya juga tidak menyebutkan tempat kedudukan kantor-kantor candu tersebut. Berdasarkan sumber lisan, tempat kedudukan Kantor Besar Candu dan Garam Surakarta terletak di wilayah Tawangmangu Karanganyar. Kantor besar candu ini mempunyai beberapa cabang yang terletak di tiap-tiap kawedanan (Wawancara dengan K.R.T Widyatmo Santo Dipuro, 20 Mei 2006: 14.00-16.00 WIB).

Walaupun pusat pemerintahan Republik Indonesia berada di kota Yogyakarta sejak tanggal 4 Januari 1946, tetapi kantor yang mengurusi masalah candu dipusatkan di Surakarta (Djogdja Documenten no.216, Djogdja Documenten no.120, ANRI, Jakarta).
Dibandingkan dengan kantor candu di Yogyakarta atau Kediri, Kantor Besar Regi Candu, dan Garam mempunyai otoritas yang besar dalam masalah distribusi dan pengelolaan candu di seluruh republik. Hal tersebut dapat dilihat dari beberapa kasus yang terjadi dalam penaganan masalah-masalah candu. Pada tanggal 22 Januari 1948, Menteri Muda Pertahanan yaitu Aroedji Kartawinata meminta Kantor Besar Regi Candu dan Garam agar menyediakan candu untuk seluruh pejuang di Jawa Timur. Komandan Teritorial Komando Jawa Timur yaitu Jenderal Mayor Dr. Moestopo diberi kewenangan penuh untuk mengambil sejumlah candu di Kantor Besar Candu dan Garam. Candu tersebut dimaksudkan agar para pejuang-pejuang di Jawa Timur dapat mempunyai bekal dan dana dalam menyusup di daerah pertahanan Belanda (Djogja Documenten no.271, Arsip Nasional Republik Indonesia Jakarta).

Kedudukan Kantor Besar Regi Candu dan Garam lebih tinggi dibandingkan Kantor Regi Candu dan Garam di Kediri, hal ini dapat dilihat pada masalah tertangkapnya dua orang pembawa candu yang diangap illegal di Blitar. Pada tanggal 2 Februari 1948, Kantor Penilik Kepolisian Jawa Timur di Blitar telah menangkap dua orang bernama Timin dan Ngarsan karena membawa candu kasar sebanyak empat besek seberat 54,5 kilogram. Dalam penangkapan, kedua orang tersebut dapat menunjukkan surat keterangan dari kementerian kemakmuran II yaitu Tjokronagoro yang diketahui oleh Perdana Menteri Amir Sjarifoedin dan Menteri Muda Keuangan, yaitu Ong Eng Die. Kasus ini kemudian dilaporkan kepada Kantor Regi Candu dan Garam di Blitar (Djogdja Documenten no. 251, ANRI, Jakarta). Kantor candu di Blitar tersebut kemudian melaporkan kasus ini kepada Kantor Besar Regi Candu dan Garam di Surakarta. Untuk selanjutnya, Kantor Besar Regi Candu dan Garam Surakarta melaporkan masalah ini kepada Kementerian Keuangan di Yogyakarta (Djogdja Documenten no. 251, ANRI, Jakarta)

Kedudukan Kantor Besar Regi Candu dan Garam Surakarta juga lebih tinggi 
dibandingkan Kantor Depot Regi Candu dan Obat di Yogyakarta. Hal itu dapat dilihat bahwa dari Kementerian Keuangan maupun dari Kementerian Pertahanan Bagian Intendans di Yogyakarta mengenai masalah candu selalu ditujukan kepada Kantor Besar Regi Candu dan Garam di Surakarta. Walaupun Kementerian Keuangan dan Kementerian Pertahanan berkedudukan di Yogyakarta, tetapi mereka jarang sekali meminta distribusi dan penjualan candu kepada Kantor Depot Regi Candu dan Obat Yogyakarta. Kemungkinan besar, kantor Depot Regi Candu dan Obat di Yogyakarta merupakan tempat penyimpanan candu (Djogdja Documenten no. 292, ANRI, Jakarta), sedangkan urusan administrasi atau kebijakan dipegang oleh Kantor Besar Regi Candu dan Garam di Surakarta. Kantor Depot Regi Candu dan Obat di Yogyakarta yang dipimpin oleh Kadarmodjo dipilih sebagai tempat penyimpanan candu dengan pertimbangan keamanan. Hal itu dikarenakan Yogyakarta merupakan pusat pemerintahan republik yang berarti juga pusat kekuatan TNI.

Kantor Besar Regi Candu dan Garam Surakarta berada di bawah kedudukan Kementerian Keuangan dan Kementerian Pertahanan Bagian Intendans yang berkedudukan di Yogyakarta. Kedua kementerian ini dapat secara langsung meminta disediakan sejumlah mata candu untuk berbagai kepentingan. Selain dua kementerian itu, Kantor Wakil Presiden juga dapat secara langsung meminta disediakan mata candu yang dibutuhkan. Hal itu bisa dilihat dari perintah Wakil Presiden Muhammad Hatta agar Kantor Besar Regi Candu Dan Garam menyediakan candu untuk keperluan gaji dan keperlaun sehari-hari pasukan dari Divisi Siliwangi (Djogdja Documenten no.248, ANRI, Jakarta). Sementara itu, kementeriankementerian lain apabila membutuhkan candu harus menghubungi atau mendapat izin dari Kementerian Keuangan, Kementerian Pertahanan Bagian Intendans, atau kantor Wakil Presiden.

Untuk lebih jelasnya mengenai struktur kelembagaan yang menangani candu pada masa revolusi, adalah sebagai berikut:

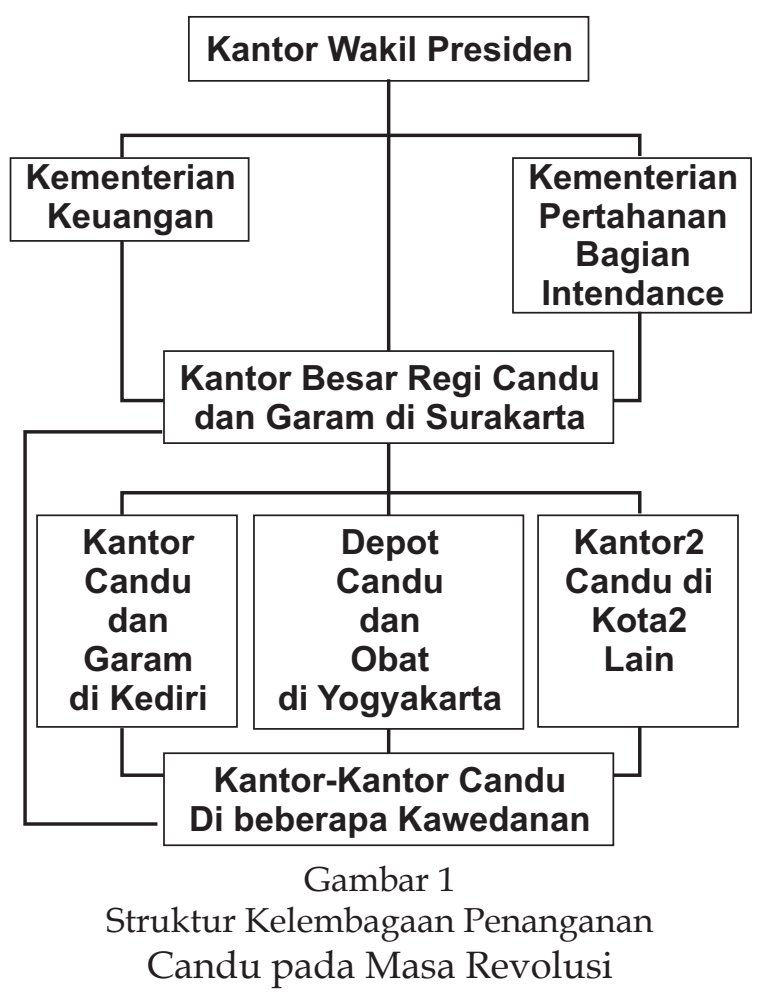

Berdasarkan struktur kelembagaan di gambar 1, terlihat bahwa penanganan candu pada masa revolusi di bawah koordinasi kantor Wakil Presiden Republik Indonesia. Kantor ini dibantu oleh dua kementerian, yaitu Kementerian Keuangan dan Kementerian Pertahanan Bagian Intendans. Kedua kementerian ini bertugas memberikan pertimbangan dan izin bagi badan-badan perjuangan dalam mendapatkan dan menjual candu. Selain itu, kedua kementerian ini juga memerintahkan penyelundupan candu ke luar negeri dalam rangka mendapatkan dana untuk perjuangan. Di bawah dua kementerian ini, ada Kantor Besar Regi Candu dan Garam yang bertugas menentukan seberapa banyak candu dapat diperoleholeh badan perjuangan dan seberapa banyak candu dapat dijual atau diselundupkan ke luar negeri. Keputusan mengenai seberapa banyak candu dapat didistribusikan atau diperdagangangkan merupakan kewenangan sepenuhnya dari Kantor Besar Regi Candu dan Garam setelah melihat persediaan candu yang disimpan di kantor-kantor candu di bawahnya.

Mekanisme permohonan candu oleh badan-badan perjuangan dapat dilakukan 
dengan berbagai cara. Permohonan yang sering dilakukan adalah badan-badan perjuangan mengirimkan surat kepada Kementerian Keuangan, Kementerian Pertahanan Bagian Intendans, atau Kantor Wakil Presiden untuk selanjutnya kementeriankementerian tersebut meminta Kantor Besar Regi Candu dan Garam menyediakan candu yang dibutuhkan. Hal itu dapat dilihat dari permintaan mata candu sebanyak 3000 tube (cepuk) (Djogdja Documenten no. 228, ANRI, Jakarta) dari Barisan Banteng kepada Wakil Presiden. Selanjutnya, Kantor Wakil Presiden melalui Sekretaris Wakil Presiden (I Wangsawidjaja) mengirimkan surat kepada Kantor Besar Regi Candu dan Garam dengan tembusan Kementerian Keuangan agar menyediakan candu secukupnya kepada Barisan Banteng (Djogdja Documenten no. 120, ANRI, Jakarta). Permintaan candu dapat pula dilakukan secara langsung dengan mengirimkan surat kepada Kantor Besar Regi Candu dan Garam yang diketahui dan disetujui oleh Kementerian Keuangan dan Kementerian Pertahanan Bagian Intendans. Hal itu dapat dilihat dari permintaan candu yang dilakukan oleh Pasukan Genie Pioner untuk membeli senjata dan pakaian. Pasukan Genie Pioner yang bermarkas di Surakarta melalui komandan batalionya, yaitu Mayor Soebakti, dengan diketahui Staf Pertahanan Kol. R.B. Soegeng dan tembusan kepada Kementerian Pertahanan dan Kementerian Keuangan meminta secara langsung sejumlah candu kepada Kantor Regi Besar Candu dan Garam (Djogdja Documenten no. 216, ANRI, Jakarta).

Walaupun kewenangan mengeluarkan candu terletak pada Kementerian Pertahanan Bagian Intendans, Kementerian Keuangan, dan Kantor Wakil Presiden, tetapi besarnya candu yang akan diberikan kepada badanbadan perjuangan atau institusi lain tergantung dari kebijaksanaan dari Kantor Besar Regi Candu dan Garam. Hal itu dapat dilihat dari penolakan Kantor Besar Regi Candu dan Garam dalam memenuhi permintaan candu dari Kantor Kementerian Pertahanan Bagian Intendans atas nama Letnan Kolonel
Suprajogi sebesar 2.812 .500 cepuk (tube) candu untuk keperluan perjuangan. Penolakan ini disebabkan candu mentah yang berada di Kediri belum dikirimkan ke pabrik-pabrik pengolahan candu di Wonosari dan Beji Klaten, sedangkan persediaan candu matang di Depot Candu dan Obat Yogyakarta menipis (Djogdja Documenten no. 216, ANRI, Jakarta).

Keputusan untuk menyetujui banyaknya candu yang akan diberikan atau dijual kepada badan-badan perjuangan atau institusi tertentu sangat tergantung dari persediaan candu. Candu yang masih mentah biasanya disimpan di Kantor Regi Candu dan Garam di Kediri. Hal ini disebabkan lahan penanaman candu yang terbesar dan milik pemerintah terletak di wilayah Kediri. Hal ini bukan berarti bahwa beberapa wilayah lain tidak terdapat areal penanaman candu. Walaupun belum diketahui secara pasti, dimungkinkan Kantor Regi Candu dan Garam di Surakarta juga mempunyai areal penanaman candu sendiri. Hal ini tidak dapat dilepaskan dari praktek-praktek pengelolaan regi candu pada masa kolonial Belanda, bahkan di Surakarta masih banyak masyarakat yang menanam candu secara illegal baik untuk dikonsumsi sendiri atau diperjualbelikan. Tanamantanaman candu yang illegal biasanya terletak di belakang rumah atau di kebun-kebun yang disamarkan atau dikelilingi tanamantanaman tertentu (Wawancara dengan Mitro Suwarno, 2 Juni 2006: 19.00-21.00).

Pabrik tempat pengolahan candu yang dikelola oleh pemerintah terletak di Wonosari Gunung Kidul dan Beji Klaten. Persediaan candu setengah matang di pabrik Wonosari pada bulan November 1948 sebanyak tiga ton, sedangkan di Pabrik Beji Klaten sebanyak satu ton (Djogdja Documenten no. 228, ANRI, Jakarta). Hal ini berarti bahwa kapasitas pengolahan pabrik candu di Wonosari lebih besar dibandingkan pabrik candu di Beji Klaten. Candu setengah matang sering disebut dengan candu kasar, sedangkan candu yang sudah matang sudah dikemas dalam tube atau cepuk. Satu tube atau cepuk beratnya 0,8 gram (Djogdja Documenten no. 228, ANRI, Jakarta). 
Berdasarkan uraian di atas maka alur distribusi dan pengadaan candu dapat diterangkan dalam gambar di bawah ini:

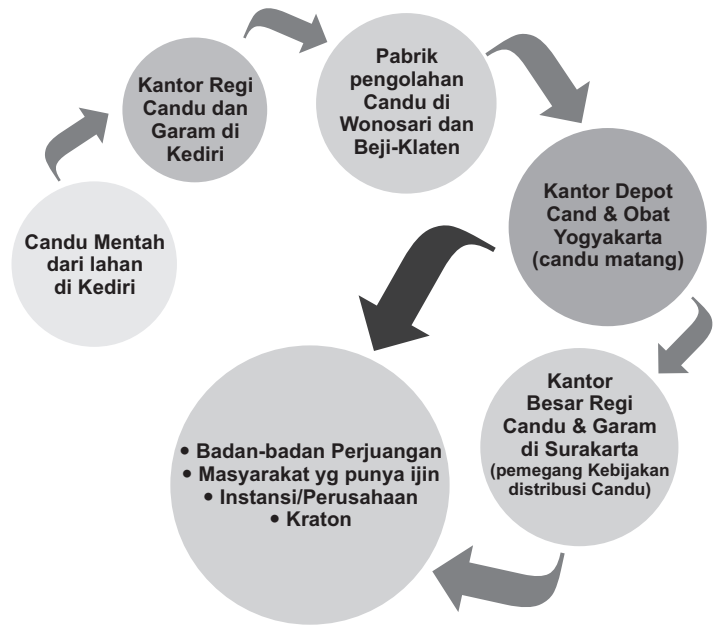

Gambar 2

Alur Distribusi dan Pengadaan Candu pada Masa Revolusi

Berdasarkan perintah dari Kementerian Pertahanan Bagian Intendans, candu yang matang dalam satu tube ditetapkan dengan harga 60 rupiah uang RI (ORI). Pemerintah memperbolehkan penjualan candu matang dalam satu tube di pasaran berkisar antara F. 3,15-3,85 (uang NICA) atau 100 rupiah uang ORI. Harga itu berlaku untuk seluruh wilayah Indonesia, kecuali Jakarta yang dijual dengan harga F.5 (uang NICA). Rupanya uang Republik Indonesia (ORI) yang beredar di pasaran bermacam-macam dengan warna yang berbeda-beda. Hal tersebut mempengaruhi harga candu yang dijual (Djogdja Documenten no. 58, ANRI, Jakarta).

Di bawah ini adalah tabel mengenai jenis uang RI (ORI) dengan nilai penjualan Candu.

Tabel 1

Nilai Uang Republik Indonesia (ORI) terhadap Nilai Uang NICA (F) Dalam Penjualan Candu

\begin{tabular}{l|l|l|l}
\hline \multirow{2}{*}{ No } & \multicolumn{1}{|c|}{ Nilai ORI } & \multicolumn{2}{|c}{ Nilai Uang NICA (F) } \\
\cline { 3 - 4 } & & Beli/tube & Jual/tube \\
\hline 1 & $\begin{array}{l}\text { ORI 100 rupiah } \\
\text { (Hijau) }\end{array}$ & 3,20 & 3,30 \\
\hline 2 & $\begin{array}{l}\text { ORI 100 rupiah } \\
\text { (Merah) }\end{array}$ & 3,15 & 3,20 \\
\hline
\end{tabular}

\begin{tabular}{l|l|l|l}
\hline No & \multicolumn{1}{|c|}{ Nilai ORI } & \multicolumn{2}{|c}{ Nilai Uang NICA (F) } \\
\cline { 3 - 4 } & & Beli/tube & Jual/tube \\
\hline 3 & $\begin{array}{l}\text { ORI 100 rupiah } \\
\text { (lembar 25) }\end{array}$ & 3,75 & 3,80 \\
\hline 4 & $\begin{array}{l}\text { ORI 100 rupiah } \\
\text { (lembar 10) }\end{array}$ & 3,80 & 3,85 \\
\hline
\end{tabular}

(Sumber: Djogdja Documenten no. 58, ANRI Jakarta)

Dalam beberapa laporan, Kantor Besar Regi Candu dan Garam di Surakarta dan Kementerian Pertahanan Bagian Intendans lebih suka menjual candu dengan pembayaran uang dari NICA. Hal itu disebabkan nilai uang NICA lebih stabil dibandingkan dengan uang ORI. Selain itu, masyarakat lebih mempercayai uang NICA dibandingkan dengan uang ORI. Terlebih penting lagi adalah uang NICA dapat dipergunakan untuk membeli senjata atau perlengkapan perang dari luar negeri. Dalam beberapa kasus, penjualan candu atau penyelundupan candu ke luar negeri dihargai dengan uang dollar (tidak diketahui secara pasti apakah itu uang dollar Amerika, Singapura atau dollar Australia). Pemerintah menargetkan satu tube candu dihargai dengan tiga dollar, tetapi seringkali target tersebut tidak tercapai dan hanya dihargai dua dollar per-tube (Djogdja Documenten no. 58, ANRI, Jakarta).

Penyelundupan atau penjualan candu keluar negeri harus dikawal oleh Angkatan Perang. Perintah ini dimaksudkan agar candu dapat dikirim atau dijual dalam kondisi aman atau tidak terjadi perampokan atau perampasan di jalan. Selain itu, kerahasiaan mengenai perdagangan candu oleh pemerintah dapat terjamin apabila tidak terjadi sesuatu di tengah perjalanan. Pengawalan terhadap pengiriman candu tidak hanya dalam rangka dijual atau diselundupkan ke luar negeri, pengiriman dari kota ke kota lain di dalam negeri juga perlu pengawalan. Upaya perampasan atau perampokan dalam pengiriman candu pernah terjadi pada saat candu dikirimkan dari pabrik candu di Wonosari ke gudanggudang candu di Yogyakarta dan Surakarta. Kurang lebih 20 orang berpakaian divisi 
Siliwangi tiruan dan bersenjata api mencoba merampok pengiriman candu di daerah antara Patok - Piyungan. Upaya itu mengalami kegagalan karena pengiriman itu dikawal oleh 30 pejuang bersenjata yang mengendarai truk. Pengawalan para pejuang terhadap aset-aset candu dilakukan pula pada pabrik-pabrik candu di Wonosari dan Beji (Djogdja Documenten no. 228, Arsip Nasional Republik Indonesia). Pengamanan ini dimaksudkan agar candu tidak dirampok, serta aktivitas pengolahan dan perdagangan candu oleh pemerintah dapat tetap dirahasiakan.

Keamanan dan kerahasiaan perdagangan candu sangat diperhatikan oleh pemerintah. Dalam sebuah surat rahasia tertanggal 15 September 1948, Kementerian Pertahanan Bagian Intendans meminta kepada seluruh BadanPerjuangandanpihak-pihakyangterkait mengenai perdagangan candu seperti kantorkantor Regi Candu agar menjaga kerahasiaan tentang masalah candu tersebut. Kementerian Pertahanan Bagian Intendans menyadari bahwa apabila aktivitas ini diketahui oleh masyarakat, maka hal ini akan menimbulkan kekacauan yang nantinya dikuatirkan akan sulit ditangani oleh pemerintah. Dalam suratnya tersebut, Kementerian Bagian Intendans juga menegaskan bahwa pihak-pihak yang boleh tahu mengenai masalah candu adalah Kementerian Pertahanan Bagian Intendans, Kementerian Keuangan, Kantor Wakil Presiden, badan-badan perjuangan yang dipercaya dapat menjual candu, dan kantor-kantor candu. Pihak-pihak di luar yang disebutkan itu diharapkan tidak tahu. Bahkan di dalam Kementerian Pertahanan di luar Bagian Intendans juga tidak diberitahu demikian juga Kementerian-Kementerian lainnya (Djogdja Documenten no.216, ANRI, Jakarta).

\section{Keterlibatan Badan-Badan Perjuangan dalam Perdagangan Candu Perdagangan di Daerah Republik}

Seperti telah dikemukakan di depan bahwa candu digunakan oleh pemerintah Indonesia untuk mendapatkan dana bagi perjuangan. Kebijaksanaan ini bersifat rahasia dan tidak boleh diketahui oleh siapapun kecuali Kementerian Keuangan, Kementerian Bagian Intendans, Kantor Wakil Presiden, dan Kantor-Kantor Regi Candu dan Garam resmi milik Pemerintah (Djogdja Documenten no.216, ANRI, Jakarta). Badanbadan perjuangan yang menginginkan candu harus merahasiakan permasalahan ini dan meminta candu dengan prosedur yang benar. Untuk lebih jelas memahami cara badanbadan perjuangan memperdagangkan candu dapat dilihat pada gambar sebagai berikut:

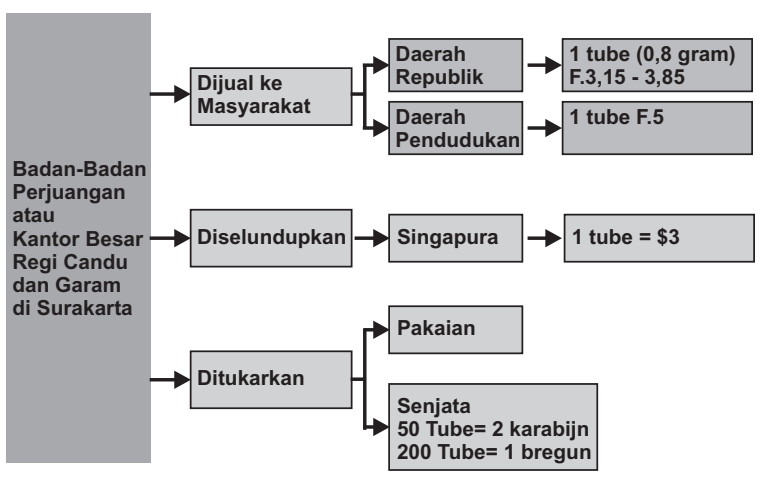

Gambar 3

Cara Badan-Badan Perjuangan Memperdagangkan

Candu pada Masa Revolusi

Pada umumnya, Badan-Badan Perjuangan membutuhkan candu untuk ditukarkan dengan senjata, biaya perjuangan termasuk gaji, dan pembelian pakaian, bahkan digunakan untuk membeli kancing-kancing baju untuk para pejuang. Barisan Banteng yang bermarkas di Jalan Purwosari no.258 Surakarta pernah mengirim surat kepada Kantor Wakil Presiden agar mendapat izin memperoleh candu dari Kantor Besar Regi Candu dan Garam. Barisan Banteng menginginkan candu dengan cara membeli sebanyak 3000 tube. Candu tersebut rencananya akan diperjualbelikan atau diselundupkan keluar negeri dan keuntungannya akan digunakan untuk membiayai perjuangan (Djogdja Documenten no. 120, ANRI, Jakarta).

Pada tanggal 19 Agustus 1948, Komandan Batalyon Genie Pionier di Jawa Tengah 
yaitu Mayor Soebekti meminta $2250 \mathrm{Kg}$ candu atau 2.812.500 tube kepada Kantor Besar Regi Candu dan Gara. Candu tersebut akan digunakan untuk ditukarkan dengan persenjataan. Nilai candu yang dapat ditukar dengan persenjataan adalah 50 mata candu dapat ditukar dengan dua senjata jenis karabin, sedangkan 200 mata candu dapat ditukar dengan satu bregun. Sisa dari penukaran candu dengan senjata akan digunakan untuk mengusahakan pakaian bagi para anggota Batalyon Genie Pionier. Menurut keterangan Mayor Soebekti, sudah ada perusahaan pakaian yang bersedia menukarkan pakaian dengan candu (Djogdja Documenten no. 216, ANRI, Jakarta). Akan tetapi, permintaan ini tidak sepenuhnya dipenuhi karena permintaan yang terlalu banyak dan persediaan candu di Surakarta dan Yogyakarta tidak cukup (Djogdja Documenten no. 216, ANRI, Jakarta).

Apabila mengamati surat dari Komandan Batalyon Genie Pionier terlihat bahwa badan-badan perjuangan atau pemerintah lebih memilih menukarkan candu kepada pihak-pihak tertentu yang dapat menyediakan barang yang dibutuhkan dari pada menjual langsung kepada masyarakat. Kenyataan ini dapat dilihat dari laporan Kementerian Pertahanan Bagian Intendans yang didasarkan laporan dari Kantor Regi Candu dan Garam yang menyebutkan bahwa Kantor Regi Candu dan Garam menukarkan sejumlah candu kepada perusahaan Astuty Trading Coy dengan bahan pakaian. Laporan dari Kementerian Pertahanan Bagian Intendans lewat Letnan I St. J. Marbun menyebutkan bahwa pada tanggal 14 Oktober 1948, Kantor Besar Regi Candu dan Garam mengelurakan candu sebanyak 22.148 dan 29.052 tube untuk ditukarkan dengan bahan pakaian sebanyak 586 Blok yang satu bloknya sebesar 30 yards (Djogdja Documenten no. 291, ANRI, Jakarta).

Di bawah ini merupakan laporan pertanggungjawaban Kementerian Pertahanan Bagian Intendans tentang penggunaan bahan pakaian sebanyak 586 blok tersebut.

Tabel 2

Pertanggungjawaban Bahan Pakaian

Hasil Usaha Penukaran Candu hingga Tanggal Oktober 1948

\begin{tabular}{l|l|l}
\hline No & Pihak yang menerima & $\begin{array}{l}\text { Banyaknya } \\
\text { Bahan Pakaian }\end{array}$ \\
\hline 1 & Jawatan Perlengkapan & 581 Blok \\
\hline 2 & $\begin{array}{l}\text { Kementerian Pertahanan } \\
\text { Bagian Intendans }\end{array}$ & 4 Blok \\
\hline 3 & $\begin{array}{l}\text { Kantor Besar Regi } \\
\text { Candu dan Garam } \\
\text { (Sebagai penghargaan) }\end{array}$ & 1 Blok \\
\hline & Jumlah & 586 Blok \\
\hline
\end{tabular}

(Sumber: Djogdja Documenten no. 291, ANRI, Jakarta)

Upaya penukaran candu dengan bahan pakaian dan keperluan lainnya dilakukan pula oleh Divisi Siliwangi. Divisi Siliwangi mendapat izin untuk menukarkan atau menyelundupkan candu sebanyak 15.000 tube/cepuk (Djogdja Documenten no. 284, ANRI, Jakarta). Pihak yang bersedia menyediakan dan mengusahakan bahan pakaian adalah Bank Negara Indonesia, P.T. Margono, dan beberapa pedagang lainnya (Djogdja Documenten no. 284, Arsip Nasional Republik Indonesia, Jakarta). Pada akhirnya Divisi Siliwangi mendapatkan beberapa jenis bahan pakaian yang ditukarkan di daerah pendudukan Belanda. Di bawah ini merupakan jenis bahan pakaian yang diperoleh Divisi Siliwangi (Djogdja Documenten no. 284, ANRI, Jakarta).

Tabel 3

Bahan Pakaian yang diperoleh Divisi Siliwangi dari Hasil Penukaran Candu Mei 1948

\begin{tabular}{l|l|l|l|l|l}
\hline No & \multicolumn{1}{|c|}{ Nama Barang } & $\begin{array}{c}\text { Banyaknya } \\
\text { (dalam Yard) }\end{array}$ & $\begin{array}{c}\text { Harga (R) Uang } \\
\text { ORI Per-yard }\end{array}$ & Total Harga (R) & Keterangan \\
\hline 1 & Black Jeans & 630 & 100 & 63.000 & 21 Blok \\
\hline 2 & White Shirting Best Quality & 1.400 & 133 & 126.000 & 35 Blok \\
\hline 3 & White Shirting Tjap Bendera & 1.120 & 132 & 147.848 & 28 Blok \\
\hline & Total & 3.150 & & 397.040 & 84 Blok \\
\hline
\end{tabular}

(Sumber: Djogdja Documenten no. 284, ANRI, Jakarta) 


\section{Penyelundupan Keluar Negeri}

Candu merupakan komoditas andalan republik dalam memperoleh dana untuk perjuangan. Candu sangat diharapkan dapat dijual atau diselundupkan keluar negeri sepertiSingapura atau Birma agar pemerintah Indonesia dapat menukarkan atau membeli senjata, mendapatkan devisa untuk membeli keperluan republik, dan dapat ditukarkan dengan emas (Djogdja Documenten no.230, ANRI, Jakarta). Selain itu, dengan cara menyelundupkan candu, maka dapat dihindari perdagangan dan penggunaan candu oleh masyarakat di dalam negeri. Badan-badan perjuangan yang tidak mau menjual langsung candu kepada masyarakat didasarkan pada perintah Kementerian Pertahanan Bagian Intendans dan Kantor Wakil Presiden. Mereka dilarang menjual langsung kepada masyarakat terutama daerah republik dan beberapa daerah pendudukan kecuali Jakarta. Pelarangan ini dimaksudkan agar candu tidak beredar luas di masyarakat dan dikonsumsi oleh masyarakat Indonesia (Djogdja Documenten no. 58, ANRI, Jakarta).

Penyelundupan candu ke Singapura baru dimulai pada bulan Juli 1947 atas perintah Perdana Menteri Amir Syarifuddin. Penyelundupan candu semakin intensif dilakukan sejak dikeluarkan perintah penyelundupan candu (candu trade) oleh Wakil Presiden Muhammad Hatta pada bulan Pebruari 1948. Berdasarkan perintah tersebut, A.A. Maramis selaku menteri keuangan memerintahkan kepada Kantor Regi Candu dan Garam di seluruh republik terutama dan Badan-Badan Perjuangan untuk melaksanakan perintah tersebut. Tugas Maramis ini dibantu oleh Mukarto Notowidigdo seorang ambtenaar opium en zoutregie di zaman kolonial Belanda. Puncak dari penyelundupan candu ke Singapura terjadi pada bulan Maret hingga Agustus 1948 (Ansori, 2013).

Tujuan penyelundupan candu keluar negeri, terutama Singapura adalah mengumpulkan dana untuk perjuangan, terutama untuk memperoleh devisa dari luar negeri. Selain digunakan untuk mendapatkan sen- jata dan keperluan-keperluan lainnya yang berhubungan dengan perjuangan, devisa dapat digunakan untuk membiayai perwakilan-perwakilan Indonesia di Singapura, Bangkon Rangoon, New Delhi, Kairo, London, dan New York (Ansori, 2013).

Penyelundupan candu ke Singapura merupakan perjuangan yang penuh risiko dan menempuh jalan yang berbahaya serta penuh tantangan. Aktivitas penyelundupan ke Singapura pada awalnya adalah cadangan komoditi perkebunan, terutama gula, karet, dan tembakau. Akan tetapi, ketatnya blokade Belanda dan sedikitnya hasil yang didapat dari komoditi tersebut, maka pemerintah Amir Syarifuddin memutuskan untuk menyelundupkan cadangancandu keSingapura. Pada umumnya, candu tidak diselundupkan secara sendiri atau terpisah dengan komoditas lainnya, tetapi ditempatkan bersamaan atau disamarkan dengan komoditas lainnya terutama gula. Sejak ada perintah tersebut, setiap penyelundupan selalu menyertakan candu dengan diselipkan di antara barangbarang selundupan lainnya (Cheong dalam Abdullah, 1997: 303).

Barang-barang komoditas perkebunan maupun candu yang diselundupkan ke Singapura biasanya melalui pelabuhan di Tegal. Angkutan laut yang digunakan adalah kapal tongkang dan speedboat. Perjalanan dimulai dari pelabuhan Tegal menuju Singapura, biasanya ditempuh selama dua Minggu dengan terlebih dahulu singgah di pulau Bangka atau Belitung. Ganasnya ombak laut dan sulitnya menerobos blokade Belanda menjadikan aksi-aksi penyelundupan menjadi cerita yang seru, menegangkan, dan melegenda. Tokoh yang banyak berperan penting dalam penyelundupan barangbarang dari Jawa melalui Tegal ke Singapura adalah Suryono Darusman (Cheong dalam Abdullah, 1997:303).

Suryono Darusman merupakan anggota misi militer Indonesia di Singapura yang terkenal dengan misi penyelundupan dengan nama "Operation Meriam Bee". Menurut Darusman, perjalanan penyelundupan dari Tegal ke Singapura penuh dengan risiko 
dan mencekam. Darusman berangkat ke Singapura beberapa hari sebelum hari Natal pada tahun 1945 dengan kapal tongkang kayu berukuran 150 ton dengan nama San Giang. Pada awalnya ia merasa kebingungan di Singapura karena tidak memiliki surat-surat identitas yang lengkap. Ia bertemu dengan beberapa orang Melayu yang membantunya di Singapura seperti Dr. Samad sampai pada akhirnya ia bertemu dengan Joe Loh seseorang berkebangsaan Cina-Singapura bekas pejuang bawah tanah dalam pasukan rahasia Inggris, force 136 yang beroperasi di Malaya melawan tentara Jepang (Darusman dalam Mochtar, 1992: 78-80).

Berkat bantuan Joe Loh, Darusman beserta tiga temannyaIzak, Mahdi, dan Bagdja berhasil mendapatkan senjata dari gudang milik sekutu di Changi Naval Base. Senjatasenjata tersebut baru dibayarkan sesampainya barang tersebut tiba di Indonesia. Senjata-senjata tersebut diangkut dengan kapal bernama Meriam Bee yang berukuran 500 DWT berada di bawah registrasi pemerintah Inggris dengan kapten kapal bernama Fraser yang berkebangsaan Skotlandia. Kapal Meriam Bee yang mengangkut 1.800 pucuk senjata lee Enfield, 6 buah meriam anti aircraft Oerlikon, alat perlengkapan dapur, dan perlengkapan seragam militer tiba di tegal pada tanggal 5 Oktober 1946. Sesampainya di Indonesia, presiden Soekarno menawarkan pembayaran barang-barang tersebut dengan tiga kemungkinan, yaitu pembayaran dengan gula pasir, pembayaran dengan perhiasan, atau pembayaran dengan candu. Pada akhirnya pembayaran diputuskan dengan 500 ton gula pasir. Dikarenakan harga gula pasir di Singapura mengalami penurunan yang drastis, maka pembayaran senjata-senjata tersebut mengalami masalah (Darusman dalam Mochtar, 1992: 80-90). Pengalaman semacam inilah yang memaksa pemerintah republik kemudian memutuskan menyelundupkan atau menjual candu ke luar negeri daripada barang-barang perkebunan yang tidak pasti harga jualnya.

Pada misi-misi berikutnya, penyelundupan barang-barang dari Indonesia termasuk candu mendapat bantuan dari kantor perwakilan Republik Indonesia pertama di Luar Negeri yang disebut dengan Indoff (Indonesia Office). Indoff berdiri setelah perjanjian Linggajati ditandatangani. Indoff dipimpin oleh Mr. Utoyo Ramelan atas perintah Perdana Menteri Syahrir. Indoff sangat berjasa bagi perjuangan republik terutama dalam hal pusat pemantauan berita dari dalam dan luar negeri dan sebagai sumber keuangan untuk membantu pembiayaan perwakilan-perwakilan RI di Luar Negeri. Sumber-sumber keuangan yang diperoleh Indoff didapatkan dari aktivitas penyelundupan dari Jawa dan Sumatera (Siti Wahyuni Sutan Syahrir dalam Mochtar, 1992: 23-24). Secara lebih rinci tugas-tugas Indoff adalah sebagai berikut:

Pertama, menjalin hubungan kerja sama dengan pemerintah setempat, yaitu "the colony of Singapore" sebagai perwujudan praktis dari pengakuan de facto atas Republik Indonesia dan pemerintah Inggris. Kedua, membentuk jalur komunikasi dengan media pers internasional, berdasarkan maksud menyajikan fakta jalannya perjuangan Republik Indonesia sebagai counter terhadap suara-suara pro Belanda yang pada umumnya telah tersebar melalui pers barat. Ketiga, mengadakan koordinasi dalam berbagai usaha (niaga atau yang lain) yang dijalankan oleh utusan-utusan Indonesia dan memakai Singapura sebagai daerah operasi. Keempat, membimbing dan memanfaatkan masyarakat Indonesia di Singapura / Malaya agar menjadi unsur pendukung perjuangan Republik Indonesia. Kelima, otorita tunggal atau satu-satunya wakil resmi pemerintah Republik Indonesia di Singapura untuk menangani masalah politik, ekonomi, dan militer (Darusman dalam Mochtar, 1992: 89). 
Urusan pengadaan dana dengan cara penyelundupan dapat dilaksanakan dengan maksimal, maka pada akhir tahun 1947 dibentuklah Trade/Finance Departement (TFD) yang berada di bawah Indoff. Tugas TFD. Yaitu (a) Menjalankan usaha dalam rangka perjuangan ekonomi Republik Indonesia berdasarkan kebijaksanaan yang ditetapkan oleh pemerintah pusat; (b) Mengumpulkan dana dan devisa untuk membiayai perwakilan Republik Indonesia di Luar Negeri; (c) Berusaha memenuhi kebutuhan esensial untuk perjuangan Republik Indonesia di dalam negeri (Darusman dalam Mochtar, 1992: 96).

Setiap candu yang diselundupkan keluar negeri harus diketahui oleh Kantor Besar Regi Candu dan Garam. Demikian pula besarnya candu yang akan dikirim ke luar negeri juga berdasarkan kebijaksanaan Kantor Besar Regi Candu dan Garam. Dikarenakan Kantor Besar Regi Candu dan Garam harus memperhitungkan cadangan candu matang yang ada, agar dapat dibagi untuk pemakaian dan perdagangan di dalam negeri maupun besarnya candu yang akan diselundupkan di luar negeri. Tidak banyak catatan yang menggambarkan penyelundupan candu ke Singapura, tetapi catatan yang ada sedikit banyak dapat menggambarkan bahwa terdapat aktivitas yang terkoordinasi antara penyediaan candu di Surakarta maupun beberapa daerah lainnya untuk kebutuhan di selundupkan ke Singapura.

Pengiriman candu dari gudanggudang candu, baik di Surakarta, pabrik candu di Beji-Klaten, maupun Wonosari ke pelabuhan-pelabuhan, terutama ke Tegal, maupun pelabuhan lainnya harus dengan pengawalan yang ketat. Hal ini dilakukan untuk menghindari sabotase atau perampokan yang dilakukan oleh pasukan-pasukan liar yang menginginkan candu untuk kebutuhan sendiri. Beberapa upaya pengawalan candu ke pelabuhan untuk diselundupkan dapat dilihat dari beberapa catatan di bawah ini.

Dalam sebuah telegram tertanggal 18 Mei 1948, dilaporkan bahwa sejumlah pasukan dari Solo dan sekitarnya telah membawa candu sebanyak dua ton untuk diselundupkan ke luar negeri. Pada tanggal tersebut, perjalanan candu baru sampai di daerah Pacitan. Candu sebanyak dua ton diperoleh dari gudang milik Kantor Besar Regi Candu dan Garam di Surakarta. Telegram tersebut mengharapkan agar pihak-pihak yang nantinya berhubungan dengan upaya penyelundupan candu tersebut agar membantu sebisa mungkin dan tidak menghalang-halanginya. Kelancaran dalam pengangkutan candu tersebut sangat penting karena kapal yang akan membawa candu ke luar negeri (mungkin Singapura) akan datang pada tanggal 15 Juni 1948 (Djogdja Documenten no. 177, ANRI, Jakarta).

Upaya pemerintah Indonesia dalam menyelundupkan candu bukan tanpa resiko. Beberapa laporan menyebutkan bahwa terdapat beberapa pejuang yang tertangkap pada saat menyelundupkan candu ke luar negeri atau ke daerah pendudukan musuh. Salah satu pejuang yang tertangkap adalah Panggabean. Ia tertangkap di Jakarta oleh pihak Belanda dengan membawa candu sebanyak 8.700 tube dan uang NICA sebanyak F. 10.000 (Djogdja Documenten no. 291, ANRI, Jakarta).

Walaupun mengandung banyak risiko, pengiriman candu keluar negeri merupakan prioritas utama pemerintah Indonesia dalam mendapatkan dana untuk perjuangan. Di bawah ini merupakan daftar candu yang telah dikirim keluar negeri yaitu Singapura sampai tanggal 2 Mei 1948 (Djogdja Documenten no. 291, ANRI, Jakarta). 
Tabel 4

Daftar Candu Mentah yang Diselundupkan ke Singapura Hingga Tanggal 2 Mei 1948

\begin{tabular}{|c|c|c|}
\hline No & \begin{tabular}{|l} 
Timbangan Kotor \\
Perhitungan Kg
\end{tabular} & Keterangan \\
\hline 1 & 88.300 & \multirow{34}{*}{$\begin{array}{l}\text { Jumlah berat kotor: } \\
3.033 .900 \\
\text { Dipotong berat } \\
\text { bungkus } \\
\mathrm{a}+14 \mathrm{~kg}=34 \times 14= \\
476 \\
\text { Berat Bersih }=2.557 .900 \\
\mathrm{Kg}\end{array}$} \\
\hline 2 & 88.300 & \\
\hline 3 & 87.600 & \\
\hline 4 & 88.700 & \\
\hline 5 & 88.500 & \\
\hline 6 & 92.500 & \\
\hline 7 & 89.---- & \\
\hline 8 & 91.300 & \\
\hline 9 & 87.500 & \\
\hline 10 & 88.500 & \\
\hline 11 & 85.800 & \\
\hline 12 & 89.---- & \\
\hline 13 & 87.800 & \\
\hline 14 & 91.500 & \\
\hline 15 & 90.600 & \\
\hline 16 & 89.300 & \\
\hline 17 & 88.200 & \\
\hline 18 & 89.---- & \\
\hline 19 & 90.500 & \\
\hline 20 & 90.700 & \\
\hline 21 & 89.---- & \\
\hline 22 & 88.400 & \\
\hline 23 & 88.300 & \\
\hline 24 & 91.200 & \\
\hline 26 & 89.700 & \\
\hline 29 & 85.500 & \\
\hline 30 & 90.---- & \\
\hline 31 & 90.800 & \\
\hline 32 & 89.200 & \\
\hline 33 & 92.---- & \\
\hline 34 & 90.300 & \\
\hline 35 & 87.300 & \\
\hline 36 & 89.400 & \\
\hline \multirow[t]{2}{*}{40} & 90.200 & \\
\hline & Jumlah: 3.033 .900 & \\
\hline
\end{tabular}

(Sumber: Djogdja Documenten no. 291, ANRI, Jakarta)

Pengiriman candu ke Singapura yang mencapai lebih dari 2,5 juta kilogram menggambarkan begitu banyaknya candu yang diselundupkan. Apabila laporan di atas per Mei 1948, berarti aktivitas penyelundupan baru berlangsung tiga bulan, yaitu Maret, April, dan Mei 1948. Dengan pengiriman sebanyak itu, maka dapat disimpulkan bahwa aktivitas penyelundupan keluar negeri berlangsung dengan intensif.

\section{SIMPULAN}

Penggunaan dan perdagangan candu di Jawa pada masa revolusi tidak dapat dipisahkan dari dinamika penggunaan candu di Jawa pada masa kolonial. Perubahan bentuk pengelolaan candu masa kolonial dari sistem bandar ke sistem regi telah menginspirasi pemerintah republik Indonesia yang baru merdeka dalam mengelola candu dengan sistem regi dan menjadikan candu sebagai dana perjuangan. Keputusan pemerintah ini bukan tanpa alasan karena kondisi sosial, ekonomi, dan keuangan yang porakporanda akibat kependudukan militer Jepang. Pemerintah republik menyadari bahwa sumber-sumber ekonomi dalam sektor pertanian dan perkebunan tidak dapat diandalkan karena sebagian besar pabrikpabrik pengolahan hasil perkebunan hancur akibat kependudukan Jepang. Kondisi ini diperparah dengan tidak berkembangnya sektor keuangan. Pemerintah harus menyediakan uang yang sangat besar untuk membeli perlengkapan perang dan menyediakan logistik atau perbekalan bagi para pejuang. Padahal pemerintah tidak memiliki devisa yang dapat dipergunakan untuk membeli senjata di luar negeri.

Untuk mengatasi masalah dana perjuangan tersebut, pemerintah secara diamdiam menggunakan candu sebagai penyediaan dana secara cepat untuk kebutuhan perjuangan. Pengelolaan candu di bawah kendali Kantor Wakil Presiden. Kantor ini dibantu oleh dua kementerian, yaitu KementerianKeuangandanKementerianPertahanan Bagian Intendans. Kementerian keuangan terlibat dalam pengelolaan candu karena hasil perdagangan candu dipergunakan untuk pembayaran gaji, pembiayaan operasional perjuangan, pembelian alat-alat perang, dan pendanaan wakil-wakil republik di luar negeri. Sementara itu, keterlibatan kementerian pertahanan Bagian Intendans karena perdagangan candu dilakukan oleh 
badan-badan perjuangan. Dua kementerian ini membawahi kantor besar regi candu dan garam yang berada di Surakarta. Kantor besar candu di Surakarta ini mengkoordinasikan kantor-kantor candu di beberapa kota, seperti kantor regi candu dan garam Kediri serta kantor Regi Candu dan Obat di Yogyakarta.

Kantor-kantor candu di beberapa kota tersebut mempunyai peranan penting dalam pendistribusian candu. Kantor Regi Candu dan Garam Kediri menyimpan candu yang masih mentah. Dari Kediri, candu yang mentah tersebut dibawa ke pabrik pengolahan candu di Wonosari Gunung Kidul dan Beji Klaten. Setelah candu matang, maka candu dikirim ke Kantor Regi Candu dan Obat di Yogyakarta atau di Kantor Besar Regi Candu dan Garam di Surakarta. Setelah itu, candu dapat didistribusikan atau digunakan oleh badan-badan perjuangan untuk dijual ke masyarakat di wilayah republik, wilayah Belanda, atau diselundupkan ke luar negeri, terutama Singapura.

\section{DAFTAR PUSTAKA}

Anshori, Irfan. 2013. Opium yang Memerdekakan Kita. Diedit oleh Ragil Koentjorodjati. <http://retakankata. com/2013/08/31/opium-yangmemerdekakan-kita/> (Diakses pada tanggal 3 April 2015).

Carey, Peter. 1984. “Changing Perception of the Chinese Communities in Central Java, 1755-1825". Indonesia, Vol. 37, hal. 1-47.

Cheong, Yong Mun. 1997. Koneksi Indonesia di Singapura, 1945-1948, dalam Denyut Nadi Revolusi Indonesia, Diedit oleh Taufik Abdullah, Jakarta: Gramedia Pustaka Utama.

Darusman, Suryono. 1992. "Operation Meriam Bee" Penyelundupan Senjata Terbesar", dalam Memoar Pejuang Republik Indonesia Seputar "Zaman Singapura" 1945-1950", Diedit oleh Kustiniyati Mochtar. Jakarta: Gramedia Pustaka Utama.
Djoko. 1970. Perdagangan Tjandu di Indonesia pada Abad ke-19. Skripsi. Jurusan sejarah Fakultas Sastra dan Kebudayaan UGM.

Ibrahim, Julianto. 2013. Opium dan Revolusi: Penggunaan dan Perdagangan Candu di Surakarta Pada Masa revolusi, 19451950, Yogyakarta: Pustaka Pelajar.

2004. "Politik Ekonomi Pendudukan Jepang di Surakarta", Humaniora, 16 (1).

Kahin, George Mc.Turnan. 1995. Nasionalisme dan Revolusi Indonesia: Refleksi Pergumulan Lahirnya Republik , Surakarta: UNS Press.

Kamajaya, Karkono.1993. Revolusi di Surakarta, Temu Ilmiah di Balai Kajian Sejarah dan Nilai Tradisional, Yogyakarta.

Kartodirdjo, Sartono. 1981. “Wajah Revolusi Indonesia Dipandang dari Perspektifme Struktural", Prisma, 8.

Mochtar, Sofyan. 1992. Kisah Pendirian "Antara Singapura" Cabang Kantor Berita Indonesia yang Pertama di Luar Negeri, dalam Memoar Pejuang Republik Indonesia Seputar "Zaman Singapura" 1945-1950", Diedit oleh Kustiniyati Mochtar. Jakarta: Gramedia Pustaka Utama.

Rush, James R. 2000. Opium to Java: Jawa dalam Cengkeraman Bandar-Bandar Opium Cina, Indonesia Kolonial 1860 - 1910, Yogyakarta: Mata Bangsa.

Salim, Ferdi. 1992. Kisah Organisasi Speedboat di Awal Kemerdekaan Republik Indonesia, dalam Memoar Pejuang Republik Indonesia Seputar "Zaman Singapura" 1945-1950", Diedit oleh Kustiniyati Mochtar, Jakarta: Gramedia Pustaka Utama.

Syahrir, Siti Wahyuni Sutan. 1992. Peran Singapura pada Tahun-Tahun Pertama Kemerdekaan Republik Indonesia: Sekelumit Kenangan, dalam Memoar Pejuang Republik Indonesia Seputar "Zaman Singapura" 1945- 
1950", Diedit oleh Kustiniyati Mochtar. Jakarta: Gramedia Pustaka Utama.

Yahya Muhaimin. 1971. Perkembangan Militer dalam Politik di Indonesia, 1945-
1966, Yogyakarta: Gadjah Mada University Press.

Zed, Mestika. 1997. "Ekonomi Indonesia Pada Masa Revolusi: Mencari Dana Perjuangan (1945-1950)", dalam Denyut Nadi Revolusi Indonesia, Diedit oleh Taufik Abdullah, Jakarta: Gramedia Pustaka Utama. 